\title{
A Pilot Study of Using Crowds in the Classroom
}

\author{
Steven Dow \\ HCI Institute \\ Carnegie Mellon University \\ spdow@cs.cmu.edu
}

\author{
Elizabeth Gerber \\ Segal Institute of Design \\ Northwestern University \\ egerber@northwestern.edu
}

\author{
Audris Wong \\ Department of Economics \\ Carnegie Mellon University \\ audriswong@cmu.edu
}

\begin{abstract}
Industry relies on higher education to prepare students for careers in innovation. Fulfilling this obligation is especially difficult in classroom settings, which often lack authentic interaction with the outside world. Online crowdsourcing has the potential to change this. Our research explores if and how online crowds can support student learning in the classroom. We explore how scalable, diverse, immediate (and often ambiguous and conflicting) input from online crowds affects student learning and motivation for projectbased innovation work. In a pilot study with three classrooms, we explore interactions with the crowd at four key stages of the innovation process: needfinding, ideating, testing, and pitching. Students reported that online crowds helped them quickly and inexpensively identify needs and uncover issues with early-stage prototypes, although they favored face-to-face interactions for more contextual feedback. We share early evidence and discuss implications for creating a socio-technical infrastructure to more effectively use crowdsourcing in education.
\end{abstract}

\section{Author Keywords}

Crowdsourcing, innovation, education, feedback.

\section{ACM Classification Keywords}

H.5.3 [Group and Organization Interfaces]: Crowdsourcing

\section{INTRODUCTION}

Educating students about innovation practices can be difficult in classroom settings, where students typically lack interaction with the real world. To facilitate a more authentic environment, many institutes have integrated interdisciplinary project-based learning approaches into their formal curricula $[10,11,24]$. While this approach effectively teaches teamwork and open-ended problem solving, students typically only receive formative feedback from a few instructors, peers, or target users. There exists a need for instructional methods and technologies that engage authentic users' opinions and realistic market forces. Can online crowds fulfill this need?

The modern Web allows anyone to leverage the scale, diversity, and immediacy of online crowds. Everyday, people can pose complex problems to the crowd [41], hire a

Permission to make digital or hard copies of all or part of this work for personal or classroom use is granted without fee provided that copies are not made or distributed for profit or commercial advantage and that copies bear this notice and the full citation on the first page. To copy otherwise, or republish, to post on servers or to redistribute to lists, requires prior specific permission and/or a fee.

CHI 2013, April 27-May 2, 2013, Paris, France.

C opyright (C) 2013 ACM 978-1-4503-1899-0/13/04...\$15.00.

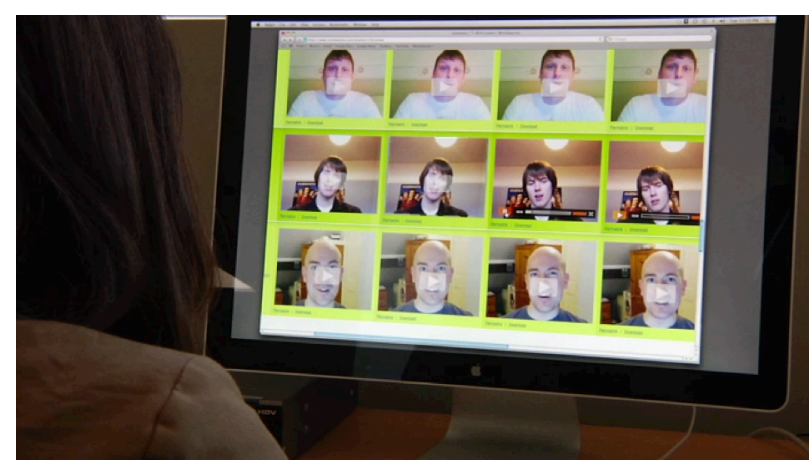

Figure 1: Student getting feedback from potential consumers on a crowdsourcing platform, MindSwarms.com

consultant to build a prototype [42], create a competition to design a logo for a new venture $[43,44]$, test two different versions of a website $[18,31,45]$, raise funds from thousands of online donors [46], or promote an idea through social networks [47] or online advertising [48].

These emerging crowd technologies are changing how people innovate. As a motivating example, two friends with an idea but few connections to capital used Facebook to get feedback on their novel coffee invention and then raised $\$ 306,944$ in 34 days on a crowdfunding platform to manufacture and fulfill orders for their product [49]. In the process of using these crowd-based technologies, they learned how to develop an innovative coffee product, how to communicate the idea, and how to manage customers' feedback - key tasks associated with innovation [12]. Eight months after launching their product, they were invited to the White House to be recognized as one of top 100 companies run by young innovators [49]. This case study illustrates the potential of crowd-based technology to support innovation learning. While many businesses have embraced crowd-based technologies [50], human computer interaction (HCI) and education researchers have yet to explore the efficacy of such techniques for innovation education.

Crowd-based technologies have the potential to transform innovation education by providing a link between the public and traditional, isolated classrooms. Our proposed approach builds on the "Learning by Design" framework where learners take on design challenges, learn principles through participation, and get feedback through regular and public interaction [20]. Further, following on Shaffer and Resnick's "thick" view of authenticity, we hypothesize that crowd-based technology makes learning more personally meaningful to the learner and connects educational activities with real-world outcomes [30]. Such an approach 
models an innovation process with real beneficiaries and benefactors and provides assessments that align instructor feedback with feedback from external parties - building on theories of cognitive apprenticeship [6].

While online crowds have the potential to shape innovation education, these resources also present a risk to students. Online crowds can be inconsistent and undereducated [17].

Online crowds may misunderstand the context for innovation and lack concern for the innovation goals and/or the learners' goals [22].

To better understand the benefits and risks of employing crowd-based methods in innovation education, we conducted a pilot study integrating the crowd into classroom settings at two universities. We explored the use of crowds on four key stages of the innovation process: needfinding to identity real world opportunities, ideating to generate novel and useful solutions to a problem, testing prototypes through feedback from potential consumers and users, and pitching novel solutions to obtain early-stage funding. Within these stages of innovation, we developed pedagogical interventions aimed to leverage different crowd-based technology (see Table 1).

In this paper, we begin by describing the limitations of contemporary approaches to innovation education and the potential benefits and risks of introducing online crowds into the classroom. We provide detailed descriptions of the interventions for the pilot course and share student reflections as captured from essays, blog entries, and a summative open-ended questionnaire. Our data suggest that while students valued the crowd as a source of cognitive stimuli during the early stages of the innovation process, they struggled with the noise and uncertainty of crowd data preferring the clarity and richness of interacting with people face-to-face as the innovation process progressed. Further, students expressed anxiety about asking the crowd, particularly friends and family, for financial resources to crowdfund their project work. We conclude the paper with a discussion of implications for creating a socio-technical infrastructure to more effectively use crowdsourcing platforms in innovation education.

\section{APPROACHES TO INNOVATION EDUCATION}

In a climate of international competition and economic uncertainty, there is an increasing need for strong innovators: individuals who can understand real problems, creatively generate solutions, build and test prototypes, and pitch and carry them forward to implementation [12]. To meet this need, innovation education has evolved to accommodate student needs through business case studies and project-based learning. Further, industry-sponsored internships and extracurricular initiatives help extend innovation education beyond the classroom [38].

\section{Business Case Studies}

In the early twentieth century, the Harvard Business School introduced case studies to provide students with historical

$\begin{aligned} & \text { Innovation } \\
& \text { Stage }\end{aligned}$
\begin{tabular}{|l|l|l|}
\hline Needfinding & $\begin{array}{l}\text { Identity real-world opportuni- } \\
\text { ties }\end{array}$ & $\begin{array}{l}\text { Special-interest } \\
\text { blogs, Twitter, and } \\
\text { Facebook }\end{array}$ \\
\hline Ideating & $\begin{array}{l}\text { Generate novel and useful } \\
\text { solutions to a problem }\end{array}$ & $\begin{array}{l}\text { Amazon Mechani- } \\
\text { cal Turk }\end{array}$ \\
\hline Testing & $\begin{array}{l}\text { Elicit feedback on prototypes } \\
\text { from potential consumers and } \\
\text { users }\end{array}$ & $\begin{array}{l}\text { MindSwarms and } \\
\text { Amazon Mechani- } \\
\text { cal Turk }\end{array}$ \\
\hline Pitching & Obtain early-stage funding & $\begin{array}{l}\text { IndieGoGo and } \\
\text { Kickstarter }\end{array}$ \\
\hline
\end{tabular}

Table 1: Our crowd-enhanced curriculum for innovation education explored a range of crowd platforms across four stages of innovation.

descriptions of actual business situations [51]. Case studies fulfilled a need that textbooks failed to provide: authentic information about an organization's products, competition, financial structure, and other factors that affect business decision-making. Students read the case studies and think through strategies the firm could employ moving forward. Through interactive discussions, students debate opposing views and begin to recognize the underlying learning objectives [51]. Many business schools have replicated and transformed this approach to bring real-world situations into the classroom.

\section{Project-Based Learning}

Beyond reading and discussion, universities increasingly integrate project-based courses into their formal curricula to give students hands-on experience seeking opportunities, taking risks, and pushing ideas into reality [21]. In these classes, student teams typically partner with an industry client to solve real-world problems and receive mentoring by expert coaches from industry. While instructors simplify the innovation process, they aim to give students an authentic experience within classroom constraints. For example, projects conclude by pitching a new product or venture to an external review board or competing in a simulated market [11]. Instructors use these final presentations and competitions as well as self-evaluation and peerassessments to assign grades to students [7,11].

Project-based classes are often taught by a single discipline, such as business [28] or engineering [10], or taught by an interdisciplinary team of instructors from these disciplines [11]. Students typically take innovation project-based classes taught as a first year cornerstone class, a senior year capstone class [10], or as an elective graduate course. Class sizes range from 16 at Northwestern University to 300 at Boston University [11]. Students find these project-based approaches to innovation education an improvement over traditional lecture-based and content-centered classes because they experience the challenges and excitement of innovation first hand [4].

While most project-based courses involve interaction in a physical classroom, a number of institutions are exploring 
online project-based learning. Students interact online with professors and industry leaders, and learn about innovation from experts throughout the world $[52,53]$. While projectbased learning and online learning experiences extend learning beyond the temporal and spatial boundaries of higher education, students demand even more real-world experiences [38].

\section{Real World Experience}

In response, many educational institutions support situated learning through industry-sponsored summer internships. Further, students are choosing to work together outside of class time on real-world projects through extracurricular activities such as robotics competitions [54], solar car teams [55], "hackathons" [56], and design studios [13]. Such student-driven initiatives emphasize the co-creation of knowledge by students, peer mentors, professionals, and faculty in a non-evaluative environment over an extended timeframe. The challenges are often complex societal challenges and demand regular testing and feedback from communities of practice [13]. Not only are such initiatives popular among students, researchers have shown they positively impact students confidence and skills related to innovation, such as applying technology to business needs [27]. This paper explores how educators may utilize online crowds to bring in more of these real-world interactions.

\section{USING CROWDS IN THE CLASSROOM}

Crowdsourcing allows someone to recruit a large group of people online to perform work towards a common goal [15]. Crowds have been tapped for numerous creative activities, such as submitting visual designs for contests [43], sketching creative combinations [40], and creating animated movies and cartoons [57].

Several properties of online crowds give it potential to use as an intervention in the classroom. It is relatively easy to hire a large crowd and to get results in a short amount of time [2]. Crowds are also relatively inexpensive to hire, especially on platforms like Amazon Mechanical Turk, where the majority of tasks pay less than one US dollar [16]. Online crowds can be diverse with people of different genders, races, nationality, languages, education, skills, and so on [29]. These crowd properties lend themselves to different aspects of innovation, such as providing inspiration through generation of sample designs [36] or feedback on existing ideas [39], where innovators seek many diverse perspectives at a low cost.

The same properties of crowds that inspire potential for innovation may also present risks. Workers on Amazon Mechanical Turk are notoriously inconsistent and often try to cut corners $[14,17]$. Simple efforts in task design, such as making the work more meaningful [5], inserting gold standard questions [17], priming workers with visual stimuli [22], and providing workers feedback [9] can improve work quality. Despite these approaches, information produced by crowds can often be noisy, ambiguous, and contradictory. Pedagogical interventions that use online crowds have the prospect of adding uncertainty to an already inexact innovation process.

\section{METHOD}

We conducted a pilot study to examine if and how crowds can support innovation in the classroom.

\section{Study Context and Participants}

Fifty students (28 male, 22 female) participated in our study. The students were enrolled in one of three human centered innovation classes offered by Carnegie Mellon University and Northwestern University. The first class was an elective masters' level class taking place at Carnegie Mellon University from January to May in 2012. The second class was a required masters' level class, while the third class was an elective undergraduate level class. The second and third classes took place at Northwestern University from April to June in 2012.

Master's students had zero to eight years of professional experience and were seeking advanced training to take leadership roles in industry. The undergraduate students were juniors and seniors and had limited professional experience. Participants' focus of study included engineering, design, psychology, education, and business.

In these classes, the students worked in 3-4 member project teams to solve real world problems ranging from helping senior citizens receive accurate and speedy prescription refills at pharmacies to promoting more accessible voting. The primary aim of the class was to provide opportunities for students to develop skills they will need for professional practice in design, engineering, and business and to adopt the habits of mind required for leadership and humancentered innovation.

\section{Pedagogical Interventions}

Like the project-based innovation classes we described above, our students engaged in traditional activities related to needfinding, ideating, testing, and pitching. They observed users in context during the needfinding stage, brainstormed ideas with their team during the ideating phase, created paper prototypes and tested them with users face-toface, and they pitched their ideas (in verbal and written format) to a live audience during mid-term and final presentations. However, to supplement each stage, we introduced the crowd-based activities described below. For each innovation stage, we describe the learning objectives, the potential for online crowds to enhance student learning, and details about crowd-based pedagogical activities.

\section{Needfinding}

Innovation students should learn how to identify and understand real opportunities to make an impact [11]. Following a needs-driven process, students learn how to engage in contextual inquiry observing consumers and their behavior in the context of their lives [3,24]. Students seek to understand diverse stakeholder perspectives, investigate all possible causes of a problem, and begin to empathize with the potential beneficiaries. From this needfinding process, 
students extract out key facts and constraints, and form opportunity statements that set the stage for ideating novel solutions.

During this stage, online crowds have the potential to help students gain a deeper understanding of needs and to stay motivated throughout their project. Social media, where crowds share intimate thoughts and concerns online, can help students tap into diverse and personal perspectives. Casting a wider net can help students avoid bias and premature solution generation. It could also have motivational benefits if students can better understand the scale and the extent of the need they are addressing.

In our courses, the needfinding intervention began with a 20-minute lecture on social media analysis. Students read case studies of how professionals collect and analyze social media to determine the needs of their users and what demands exist for certain solutions. As a take home assignment, students were asked to conduct three in-person interviews and to harvest at least fifty comments or blog entries from one or more online forums that talk about the problem space. During class, students shared and collaboratively analyzed their preliminary findings with students from other teams and later delivered a short presentation of their social media data analysis and the key opportunities areas in class.

\section{Ideating}

Student innovators must learn to generate or produce solutions that are both novel and useful [32]. To support creative problem solving, students typically learn techniques for group brainstorming where people generate a large quantity of solutions to a given problem [26]. Quantity increases the likelihood that one will be successfully implemented [34].

Online crowds have the potential to significantly increase the number of valid ideas on the table, but only if the crowd understands the problem space and contextual constraints. The diverse demographics of crowds can produce an abundance of ideas that either confirm or expand students' thinking and give them more paths forward.

In our courses, the ideation intervention began two weeks after the first intervention with a 20-minute lecture on different brainstorming and synthesis techniques [19,26] and the operational details of using Mechanical Turk (getting an account, paying, designing a task, etc). First, students were asked to generate at least 50 ideas on their own. Then, student teams were asked to recruit 40 crowd workers to generate at least 5 ideas each with the goal of seeding 200 or more ideas for their problem space. Students used one or more synthesis techniques and narrowed the idea space down to about six possible solutions that could be prototyped in the next phase of the project. During an inclass critique, students described their ideation process and presented the top three to six of their most promising ideas from both the crowd and their own brainstorming session.

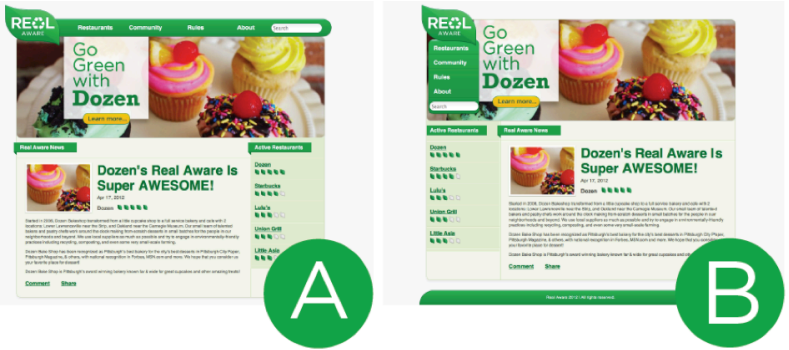

Figure 2: Screenshot of one student teams' alternative designs for A-B testing on Amazon's Mechanical Turk.

\section{Testing}

While many people have creative ideas, testing a concrete manifestation of an idea helps student innovators yield rich feedback from users, peers, and experts [23]. Prototypes help people construct new knowledge through hands-on experimentation [35]. When creating prototypes, students reason about uncertainty, make estimates, and choose among alternatives [10].

At this stage, online crowds have the potential to generate formative feedback that can help students shape specific design solutions. Students potentially find value in the rapid turnaround and the authenticity of getting input from an audience outside of instructors and classroom peers.

For this stage of innovation, we attempted two different interventions for obtaining feedback from crowds: online "speed dating" [8] and A-B testing [18]. Course lectures covered storyboarding, "speed dating", wireframing, Web analytics, and A-B testing. At CMU, students sketched storyboards for six of their proposed solutions and then gathered feedback online using a service called MindSwarms ${ }^{1}$, where consumers record one-minute long responses to questions [58]. Each of the team's six storyboards yielded twenty-eight video clips. The following week, students presented their findings about how people reacted to their ideas and provided rationale for which idea(s) they were going to develop into a prototype.

The courses at CMU and Northwestern University both offered a unit on A-B testing. Students created two different solutions to compare (see Figure 2). CMU students created working Web prototypes; NU students created wireframes. Students hosted their solutions online, installed Google Analytics to collect usage data, and prepared an online questionnaire to gather qualitative feedback. Student teams were asked to solicit feedback and usage data from at least thirty workers on Mechanical Turk. Students shared the results of their A-B testing during in-class presentations.

\section{Pitching}

In innovation education, students learn to clearly and succinctly state the problem and promote their proposed solution [25]. Students learn basic communication concepts including audience, genre, and purpose [24]; they also

\footnotetext{
${ }^{1}$ MindSwarms typically charges a professional fee, but provided limited access to students for free to support this research.
} 
practice communicating with clients and peers using text, graphics, charts, and oral presentations. Instructors increasingly require students to use basic video editing in programs such as iMovie to present their concept to a panel of "experts" at the end of the semester.

At this stage, online crowds have the potential to serve as an "authentic" audience to judge the efficacy of student solutions. This authenticity can encourage students to continually refine their pitch to connect with diverse audiences. Moreover, it can give students an opportunity to vet solutions that may have real market potential.

In our courses, the pitch project followed two weeks after the prior intervention. Lectures covered crowdfunding, early-stage funding, and the basic components of a crowdfunding campaign. For their main assignment, student teams created an IndieGoGo or Kickstarter crowdfunding campaign. Students wrote a script, sketched a storyboard for a video, and then produced a video no longer than three minutes. To promote their campaign, students wrote a project description for the crowdfunding platform, designed a reward structure for their funders, and created shorter versions of their project description appropriate for different social media (ex. Facebook, Twitter, etc). Student teams gave final presentations of their crowdfunding pitch in class. Northwestern students did not have time to launch their campaigns due to their shorter ten-week term. The Carnegie Mellon students launched and promoted their crowdfunding campaigns for four weeks and shared their campaign results in the final presentation.

In all, the total in-class time devoted to these four crowdbased interventions was approximately four hours out of a possible 40-60 hours of instruction.

\section{Data Collection}

Throughout the term, the main co-authors (who also served as course instructors) collected observations of students' attitudes and actions related to the pedagogical interventions. We collected written reflections after each intervention and the "raw input" provided by the crowd. At the conclusion of the course, all students completed a thirtyminute online survey in Qualtrics [59] asking them to reflect on each of the four crowd-based interventions. Survey responses were anonymous with a response rate of $100 \%$. The survey primarily investigated these questions:

- How did students react to crowd-enhanced interventions in the innovation process?

- Does interacting with the crowd throughout the innovation process influence the products and services they create, and if so, how?

\section{Data Analysis}

We employed selective coding and analysis to understand the experience of crowd-based interventions [33]. First, we read through all of the responses, flagging each instance where students described their experience with a particular intervention. We did not have a categorization scheme a priori since we did not know how students' would react to crowd-based interventions. After identifying instances of experiences, we clustered them into conceptual categories. At this stage of the research, we were interested in capturing students' overall perceptions of crowd work and how these may have evolved throughout the course. The data is primarily qualitative and we report the quotes in the original form as provided by the students.

\section{FINDINGS}

Our findings cover the courses from both Carnegie Mellon (CMU) and Northwestern (NU). We report initial findings according to four stages of the innovation process: needfinding, ideating, testing, and pitching. In each stage, we identify opportunities and challenges with the goal of better understanding how we engage the crowd in innovation education.

\section{Needfinding: Social Media Help Uncover Diverse Needs} Our evidence suggests the crowd can support innovation education by helping students to identify and scope real world opportunities. Engaging with the crowd is particularly useful at the beginning of the innovation process when students have limited domain expertise and need a broad understanding of the problem space. On average, students consulted twenty-three different web sources and collected data from about fifty perspectives. A graduate student described social media as a "stepping off point" for the project and useful for "researching the scope of possible ideas." A graduate student in engineering remarked, that the social media analysis was particularly "useful when we [were] less familiar with pain points in the field." Another student described the social media analysis as "very cool," because it provided a compelling way to quickly survey an unfamiliar domain using a familiar medium.

Many students perceived the social media analysis as more efficient than other qualitative research methods. One student compared the efficiency of social media analysis to the often time-consuming process of arranging and conducting qualitative interviews with stakeholders:

"...it would have taken us a lot longer to conduct the same amount of research and to structure our project."

While efficient and inexpensive, students identified limitations of the social media analysis. Although many opinions are captured in social media, some populations of interest share less. Students struggled to conduct a social media analysis for crowds with low web visibility. An undergraduate design student remarked:

"I don't think social media helped at all since it was a project based on helping [a specific] community and there isn 't much social media on [this particular community]".

Because of the lack of existing social media on his chosen topic, the student created a Facebook page asking his 
friends to comment on their personal experience with the problem he was tackling. Within 24 hours, the page had over 100 "friends" who had contributed comments about their experience. In class, he expressed surprise and satisfaction that so many people had thoughts to share, but had no outlet for doing so.

Once the social media data was collected, the students categorized the remarks according to behaviors, feelings, and thoughts. Due to the abundance and richness of the data, many students requested more time to analyze the data. One student complained that she did "not have enough time" to fully analyze the rich data she had collected. Another student reiterated her concern that she was both learning a new data collection technique (social media mining) as well as an analysis technique.

"The instruction was not clear to those who do not have an HCI background."

In addition to more time spent in analysis, students also wanted to better understand the history and case studies of using social media in the innovation process. One student offered a particular suggestion.

"I would have liked to have had more time learning how the designers of those services used such tools."

While students found social media useful during the early stages of the understanding process, the usefulness of social media mining declined as students narrowed their project scope and better understood their problem domain. As one student explained,

"It seemed to just confirm information that we had already known."

After the initial excitement of understanding stakeholders using social media, students admitted to preferring the richness of contextual inquiry. A student noted: "Talking to people in context was far more interesting."

The evidence suggests that social media analysis provides a rapid research tool for understanding a problem space in very early stages; however, contextual inquiry remains critical and preferable for revealing deeper insights.

\section{Ideating: Crowds Produce a Large Quantity of Ideas}

Our findings suggest that Mechanical Turk was helpful for generating a large number of ideas for the problems the students identified during the needfinding process. However, students were disappointed in the quality.

On average, teams generated 74 unique solutions on their own. Teams then paid an average of 28 MTurk workers $\$ 0.25$ to generate 5 ideas each, yielding a total of about 140 ideas per group, and roughly $75 \%$ of ideas were unique. An undergraduate student described the pleasure and usefulness of generating ideas with the crowd: "I really liked building up this massive number of ideas."
Not only was ideating with the crowd fun and helpful for generating a large number of ideas, students found the ideation process liberating. A master's student described her experience. "We got to let loose and create more crazy ideas, which was enjoyable."

However, ideation requires not only generating a large number of novel ideas but also generating useful ideas. Students expressed disappointment with the crowd's ability to generate useful ideas. One master's student explained:

"The quality of the responses was too low and I don't think even one of the Turker's ideas made it into our final 10."

In addition to the low quality, students found the responses to be redundant to other respondents in the crowd. One undergraduate student reported: "MTurk ideas are largely overlapping with each other."

Should the quality of ideas improve, students felt that individuals in the crowd should be identified and credited for their contribution. A student generating ideas for her project reported her concern:

"I don't know if it's valid to just use the idea from Turkers without giving them any credit."

We found students were motivated to work with the crowd to generate a large quantity of ideas, however they expected the same quality that might result from working with an established team member who understands the context and is incentivized to generate high quality ideas. With overly high expectations, students may lean on the crowd for ideas, rather than simply using the ideas as a springboard towards a more refined concept. This can be particularly problematic for students new to working with the crowd and learning the innovation process.

\section{Testing: Crowds Helped Shape Student Concepts}

Our data suggest that online crowds can support classroom innovation by providing students with feedback on prototypes. Students praised the speed and diverse points of view, but also commented on the lack of interactivity from the particular crowd tools used for this intervention. At CMU, where students got video-based feedback on earlystage storyboards from participants at MindSwarms, one student praised the speed of the crowd feedback:

"I can't think of other better ways to get a lot of user input very quickly."

The students found the crowd to represent of a "broad" set of target users. A student working on a redesign of a service commented:

"[MindSwarms] was great tool that helps designers connect with potential target people easily."

Another student explained the usefulness of crowd feedback as obtaining "different opinions from each other." As expected, students used the feedback to inform the next 
steps of their project. A student explained: "[It] helped direct and improve our design of prototype."

Although many students described the feedback from MindSwarms as "better" than the feedback received through Mechanical Turk, students were more suspicious of the veracity of the feedback. A student described her concern:

"I have the nagging feeling that the people were too positive and were just trying to guess which answer we wanted in order to make us happy."

Another downside to the particular crowdsourcing platforms selected for prototyping and testing was that neither enabled back and forth interaction with the crowd. A master's student explained:

"I think [MindSwarms] is better than MTurk, but still, I'm not sure if that's a good way to do evaluation because we cannot instruct people about the correct way to understand our ideas."

Similarly, another student reported:

"We can't really interact with [the crowd]... [I] have follow up questions... to figure out what they think and want."

Unlike testing concepts with close friends or family, testing with the crowd prevented students from clarifying their concepts when collecting feedback or reconnecting with users at later stages in the testing.

The usefulness of the feedback may have also been affected by the student's ability to express their ideas in different media. Students who struggled to communicate their ideas found it intimidating to test ideas with the crowd. One student explained the relationship between his technical drawing skills and his enjoyment with the testing phase.

"I did not enjoy this [stage] much mainly because I'm not very good at getting my ideas across through drawings. This is something I need to work on."

At both CMU and NU, students conducted A-B testing and recruited participants from MTurk. While students again reported enjoying learning about A-B testing and specific crowd-based platforms, several students suggested that they were not quite ready for this level of A-B testing.

"I felt that the amount of time available and the fidelity of the prototype does not provide a strong case for $A-B$ tests or web analytics. It could have been better to test the usability of the interface using techniques like think-alouds with less number of users. I feel that would have given us more insights compared to log analysis and A-B testing."

A student reiterated the point that A-B testing is perhaps best reserved for higher fidelity prototypes.

"I think the A-B test and Web analytics would be more useful for a complete system, or prototype with several screens. A think aloud test could have been more useful."
Students seemed to prefer communicating with people who could give them rich feedback. One student disliked talking with users entirely and would have preferred receiving feedback from peers during class time: "I preferred the small feedback sessions with smaller groups."

Another student reiterated her enthusiasm, reporting:

"I love learning from my classmates, hearing about their ideas, and receiving feedback from them!"

Overall, students benefited from their interactions with online crowds, but they wanted richer, more interactive communication. This suggests that online crowds may serve best as a supplement to face-to-face techniques for helping students get feedback on innovation concepts.

\section{Pitching: Crowds Demand Accountability}

Our data suggest that while students found preparing pitches for a crowdfunding campaign useful, launching and running an actual campaign was challenging due to the added responsibilities and pressure of delivering a product or service after the class ended.

Students began by researching the requirements for either the IndieGoGo or Kickstarter crowdfunding platforms and then opened an account. Next, they wrote a pitch to identify and direct their appeal to a target audience. Students also storyboarded scripts, and recorded and edited 1-3 minute video using simple video editing software such as iMovie. This activity caused them to consider the potential differences between users (those who use) and financial backers (those who provide financial resources) and motivations for backing a project.

Whether they launched their campaign (CMU students) or not (NU students), all students prepared budgets for executing their campaign. Budgets ranged from $\$ 1,310$ to $\$ 14,000$. The CMU students who actually launched their campaigns raised an average of $\$ 391$, approximately $22 \%$ of the combined funding goal. No groups met their funding goal, but one raised as much as $\$ 870$ (64\% of their goal).

Overall, students appreciated what they learned by going through the steps of creating a pitch, as one student said:

I enjoyed this project because this skill of pitching an idea will be need[ed] ... in my future work.

Another student reiterated the real-world nature of the activity and the confidence it fostered.

"It gave me the feeling that I could plan and execute a decent crowdfunding campaign for real when I needed money for a venture."

Students learned about the repetitive nature of pitching and the necessity of asking again and again. One student commented: "I learned crowdfunding is tedious."

While students found crowdfunding novel, they were uncomfortable asking people in their network for financial support, despite evidence that campaigns typically first gain 
momentum through close ties [60]. A student described her concern for asking for money when she felt she could not provide a valuable reward for investing.

"I think the experience of conducting a [crowdfunding] campaign is interesting... [but] I am concerned about the fund raising, especially from close friends and family. It feels that asking for a hundred dollar gift from your friend [is not fair], when we have [nothing] to return to them."

Another student reiterated this concern about the motivations required to run a successful crowdfunding campaign.

"The main problem with the crowdfunding piece of the class was that few students, as far as I could tell, actually wanted to raise the money. Most students in the class have other plans and weren't planning to continue working on their idea. Crowdfunding is great if you are passionate about an idea and really driven to make it happen, but the context of a course project didn't quite fit that."

While the instructors explicitly told students they would not be graded on how much funding they raise, many students expressed disappointment when they did not reach their funding goal and they realized the majority of fundraising came from friends and family. A student explained:

"As most of our funding is from the friends or family. I felt sad [about] this result."

Students discounted the financial backing as positive feedback because most of the funding came from friends and family.

"Next time [the class should] just ask for and collect money from strangers so it's a real way to test whether or not you have a good pitch of your project, not anything else."

Most students would prefer not to rely on friends and family at all. But as one student explained, he could envision asking for support if his intentions were true.

"To me it wouldn't be awkward at all just to ask my family or friends to do things if I decided to do it for real. I think the most awkward point, to me, is that in my pitch video I talked about 'we see this problem and we'd like to do this', but in our minds, we already know that this is just going to be a prototype that cannot be put in the real world. So that made me feel really weird about asking my friends and family, because they say 'so is it going to be a real thing?' and when I say 'no' then 'why should I donate?',

A handful of students did not consider pitching as a critical skill for innovators, and consequently, they were hesitant to participate in crowdfunding. "I don't understand how it relates to creativity in any real manner."

Overall, students valued the experience of preparing materials for a crowdfunding campaign. However, launching the actual campaign proved challenging to students who did not have ideas they actually wanted to pursue. Consequently, they resented the responsibilities and expectations required for actual implementation.

\section{Overall Student Impressions}

Students enjoyed using contemporary tools, referring to them as "novel" and "cool." As one student remarked:

"Being exposed to sites like Kickstarter ...learning about tools out there to get feedback, [and] talking to more people ... was interesting."

Students were also attracted to the idea of interacting with people beyond the walls of their classroom. As one student described:

"I've learned in this project how great it can be to connect people and share ideas."

Further, the inexpensive and targeted interaction appealed to students who were strapped for cash and time.

\section{DISCUSSION}

Increasingly, students, industry, and the academy demand educational experiences that bridge to real-world situations. Online crowds provide one potential solution. This solution ties deeply into two ongoing trends. 1) Many students increasingly turn to the crowd to find information and to connect through social networks; our solution embraces these behaviors in an educational setting. 2) To have a successful career in HCI or innovation, students will need to be prepared to learn skills such as crowdsourcing, data mining, and online experimentation.

The research reveals many advantages and challenges of engaging online crowds in the classroom. In the early stages of the innovation process, crowds helped uncover diverse needs for students. As the process progressed into the ideating and testing stages, students valued the relative ease of obtaining a large quantity of feedback from online crowds, but were often disappointed with the low quality due to the lack of context. In general, students were positive about creating crowdfunding campaigns, however launching the actual campaign proved challenging to students who did not have ideas they actually wanted to pursue. These outcomes supported our focus on teaching students how to gather, analyze, and take action based on data from online crowds. As instructors, we are more concerned that students learn new methods (process outcomes), rather than produce novel innovations (product outcomes).

While online crowds elevated the amount of information and the authenticity of their projects, we use the emerging key challenges to propose three guiding design principles for future crowd-enhanced courses: 1) set expectations, 2) enable deeper interactions, and 3) handle uncertainty.

\section{Set Expectations}

When integrating the crowd into the classroom, instructors should set expectations appropriately. For needfinding and ideating, crowds seem to be most useful for stimulating cognition, not supplanting it. Instructors can introduce 
crowd-enhanced activities alongside other HCI creativity support tools such as Idea expander [37] and Momentum [1], which display images to facilitate team ideation. While such tools are generally helpful, in some cases, they can be distracting or provide too much stimuli when focused attention is needed. Like professional innovators, students need to learn when more or less stimulation is needed.

\section{Enable Deeper Interactions}

Crowd-based interactions are designed for resource exchange, be it financial or information. While engaging with the crowd lowers the cost and speed of this exchange, it potentially increases the quantity of resources available to the student, and indirectly, the responsibility required by the student to appropriately manage the resources. When launching their crowdfunding campaigns at CMU, many students asked for financial resources they did not desire or intend to follow through with. We suggest concluding the class with a completed, but un-launched campaign so that students do not need to have interactions for which they cannot follow through. If funding is a component, instructors need to teach students how to get funding from people other than friends and family.

\section{Handle Uncertainty}

Students need instruction on how to manage uncertainty, inherent in both working with the crowd and conducting an innovation process. Upon entering higher education, few students have had to competently deal with uncertainty. Rather they are accustomed to instructors and parents handling this for them. To mitigate some of these risks and to ensure that students learn, our crowd-enhanced classes kept conventional course mechanisms in place. Instructors gave detailed input on student projects at every stage. Students also provided peer-to-peer feedback during inclass critiques. Further, instructors shepherded student teams by scaffolding students on how to interact with crowds, providing tutorials on how to sort and analyze feedback, and advising teams on how to discern valuable crowd insights from noise.

\section{FUTURE WORK}

Given the initial appeal and success of these interventions, it is reasonable to assume that online crowd can supplement innovation education. Yet more study is needed to understand the mechanisms and refine the instructional methods around crowds. Based on what we learned in this pilot study, we intend to examine the qualities of crowd-based platforms that best support relevant and high-quality feedback for project based course activities. This focus will allow us to conduct comparative studies on characteristics of crowd-based platforms that we believe will impact the feedback including: (a) expertise in domain, (b) channel of communication (synchronous vs. asynchronous; text vs. video) (c) motivation to give feedback (intrinsic vs. extrinsic), and (d) relationship to the students (anonymous vs. identifiable; one-time vs. multiple interactions).
Moreover, we will create and disseminate new instructional materials to support crowd-enhanced learning that teachers can adopt in their own settings. We will develop lectures and in-class activities for students to practice collecting and analyzing data with the support of the instructor as well as a database of case studies for instructors to demonstrate the how crowds inform professional practice. A long-term goal is to understand how the instructor's role will change as new methods for engaging external audiences become available and valuable for students.

\section{CONCLUSION}

Higher education is criticized for being out of touch and therefore inadequately preparing students for the real world. The Internet offers unprecedented opportunities to break down the barriers between higher education and the real world. We have asked if and how the classroom can be enhanced through interactions with the crowd. Answering this question through a pilot study of a crowd-enhanced curriculum has revealed new opportunities and challenges for using such systems in a learning environment.

\section{ACKNOWLEDGEMENTS}

We thank our students for their participation, and MindSwarms for educational access to their service. This work is funded through NSF Grant IIS-1217096.

\section{REFERENCES}

1. Bao, P., Gerber, E., Gergle, D., and Hoffman, D. Momentum: getting and staying on topic during a brainstorm. Proc of conf on Human factors in computing systems, ACM (2010), 1233-1236.

2. Bernstein, M.S., Brandt, J., Miller, R.C., and Karger, D.R. Crowds in two seconds: enabling realtime crowd-powered interfaces. Proc ACM symposium on User interface software and technology, ACM (2011), 33-42.

3. Beyer, H. Contextual Design: Defining Customer-Centered Systems. Morgan Kaufmann, 1997.

4. Blumenfeld, P., Soloway, E., Marx, R., Krajcik, J., Guzdial, M., and Palincsar, A. Motivating Project-Based Learning: Sustaining the Doing, Supporting the Learning. Educational Psychologist 26, 3 (1991), 369-398.

5. Chandler, D. and Kapelner, A. Breaking monotony with meaning: Motivation in crowdsourcing markets. University of Chicago mimeo, (2010).

6. Collins, A., Brown, J., \& Holum, A. Cognitive Apprenticeship: Making Thinking Visible. American Educator, 6-46.

7. Cynthia J Atman, D.K. Characterizing design learning: A mixed-methods study of engineering designers' use of language. (2008).

8. Davidoff, S., Lee, M.K., Dey, A.K., and Zimmerman, J. Rapidly Exploring Application Design Through Speed Dating. Proceedings of Ubicomp, (2007).

9. Dow, S.P., Kulkarni, A., Klemmer, S.R., and Hartmann, B. Shepherding the Crowd Yields Better Work. In Proc of Computer Supported Cooperative Work, (2012).

10. Dym, C.L., Agogino, A.M., Frey, D.D., and Leifer, L.J. Engineering Design Thinking, Teaching, and Learning. Journal of Engineering Education 94, (2005), 103-120. 
11. Fixson, S.K. Teaching Innovation through Interdisciplinary Courses and Programmes in Product Design and Development: An Analysis at 16 US Schools. Creativity and Innovation Management 18, 3 (2009), 199-208.

12. George, J.M. 9 Creativity in Organizations. The Academy of Management Annals 1, 1 (2007), 439-477.

13. Gerber, E., Olson, J.M., and Komarek, R. Extracurricular Design-Based Learning. International Journal of Engineering Education 28, 2 (2012).

14. Heer, J. and Bostock, M. Crowdsourcing graphical perception: using mechanical turk to assess visualization design. Proceedings of the intl conference on Human Factors in Computing Systems, ACM (2010), 203-212.

15. Howe, J. Crowdsourcing: Why the Power of the Crowd Is Driving the Future of Business. Crown Business, 2008.

16. Ipeirotis, P.G. Analyzing the Amazon Mechanical Turk marketplace. XRDS: Crossroads, The ACM Magazine for Students 17, 2010, 16-21.

17. Kittur, A., Chi, E.H., and Suh, B. Crowdsourcing user studies with Mechanical Turk. Proc of conference on Human factors in computing systems, (2008), 453.

18. Kohavi, R., Henne, R.M., and Sommerfield, D. Practical guide to controlled experiments on the web: listen to your customers not to the hippo. Proc of ACM intl conf on Knowledge discovery and data mining (2007), 959-967.

19. Kolko, J. Abductive Thinking and Sensemaking: The Drivers of Design Synthesis. Design Issues 26, 1 (2011), 15-28.

20. Kolodner, J., Hmelo, C.E., and Narayanan, N.H. Learning by Design ${ }^{\mathrm{TM}}$ from Theory to Practice. In Proc of Intl Conference of the Learning Sciences, (1998), 16-22.

21. Kuratko, D.F. The Emergence of Entrepreneurship Education: Development, Trends, and Challenges. Entrepreneurship Theory and Practice 29, 5 (2005), 577-598.

22. Lewis, S., Dontcheva, M., and Gerber, E. Affective computational priming and creativity. Proc of the conf on $\mathrm{Hu}$ man factors in computing systems, ACM (2011), 735-744.

23. Lewitt, T. Creativity Is Not Enough. Harvard Business Review, 2002.

24. Mckenna, A.F., Colgate, J.E., Carr, S.H., and Olson, G.B. IDEA: Formalizing the Foundation for an Engineering Design Education. International Journal of Engineering Education 22, 3 (2006), 671-678.

25. Miron, E., Erez, M., and Naveh, E. Do personal characteristics and cultural values that promote innovation, quality, and efficiency compete or complement each other? Journal of Organizational Behavior 25, 2 (2004), 175-199.

26. Osborn, A.F. Applied Imagination: Principles and Procedures of Creative Problem Solving. Charles Scribner's Sons, 1963.

27. Peterman, N.E. and Kennedy, J. Enterprise Education: Influencing Students' Perceptions of Entrepreneurship. Entrepreneurship Theory and Practice 28, 2 (2003), 129-144.

28. Plaschka, G. and Welsch, H. Emerging Structures in Entrepreneurship Education: Curricular Designs and Strategies. SSRN eLibrary, (1990).
29. Ross, J., Irani, L., Silberman, M.S., Zaldivar, A., and Tomlinson, B. Who are the crowdworkers? In extended $a b-$ stracts on Human Factors in Computing Systems, (2010).

30. Shaffer, D.W. and Resnick, M. "Thick" authenticity: new media and authentic learning. J. Interact. Learn. Res. 10, 2 (1999), 195-215.

31. Siroker, D. How Obama Raised $\$ 60$ Million by Running a Simple Experiment. 2010. http://blog.optimizely.com/howobama-raised-60-million-by-running-an-exp.

32. Sternberg, R.J. Handbook of Creativity. Cambridge University Press, 1998.

33. Strauss, A.C. and Corbin, J.M. Grounded Theory in Practice. Sage Publications, Inc, 1997.

34. Terwiesch, C. and Ulrich, K. Innovation Tournaments: Creating and Selecting Exceptional Opportunities. Harvard Business Press, 2009.

35. Thomke, S.H. Experimentation Matters: Unlocking the Potential of New Technologies for Innovation. Harvard Business Press, 2003.

36. Tidbell, B., Mulder, I., and Stappers, P.J. Online Design Contests: A Network of Inspiration for Designers. (2011).

37. Wang, H.-C., Cosley, D., and Fussell, S.R. Idea expander: supporting group brainstorming with conversationally triggered visual thinking stimuli. Proc of ACM conf on Computer Supported Cooperative Work, (2010), 103-106.

38. Westerberg, C. and Wickersham, C. Internships Have Value, Whether or Not Students Are Paid. The Chronicle of Higher Education, 2011.

39. $\mathrm{Xu}, \mathrm{A}$. and Bailey, B.P. A crowdsourcing model for receiving design critique. In extended abstracts on Human Factors in Computing Systems, ACM (2011), 1183-1188.

40. Yu, L. and Nickerson, J.V. Cooks or cobblers?: crowd creativity through combination. Proc of ACM conf on $\mathrm{Hu}$ man Factors in Computing Systems, (2011), 1393-1402.

41. Innocentive. www.innocentive.com.

42. oDesk. https://www.odesk.com.

43. 99designs: http://99designs.com/.

44. Crowdspring. www.crowdspring.com.

45. Optimizely. www.optimizely.com.

46. Indiegogo. www.indiegogo.com.

47. Facebook. www.facebook.com.

48. Google Ad Words. https://adwords.google.com.

49. Coffee Joulies on Kickstarter. http://www.kickstarter.com/projects/705847536/coffeejoulies-your-coffee-just-right.

50. Open Innovation. www.openinnovation.net.

51. Case Study. http://en.wikipedia.org/wiki/Case_study.

52. Coursera. www.coursera.org.

53. Stanford Technology Ventures. http://stvp.stanford.edu/.

54. FIRST Robotics Competition. www.pittsburghfirst.org/.

55. Solar Car Teams. http://en.wikipedia.org/wiki/List_of_solar_car_teams.

56. Tartan Hacks. www.tartanhacks.com.

57. Newgrounds. http://www.newgrounds.com/.

58. MindSwarms. www.mindswarms.com.

59. Qualtrics. www.qualtrics.com.

60. IndieGoGo blog. http://www.indiegogo.com/blog/. 